\section{Intersecções entre cuidados paliativos e homossexualidade}

Fernandes, Higor Esturião

Escola de Ciências da Vida, Programa de Pós-Graduação em Bioética da Pontifícia Universidade Católica do Paraná, Curitiba,PR,Brasil E-mail: higorsturiao@gmail.com

\section{Silva, Weslley Yago Leal da}

Complexo Hospital de Clínicas da Universidade Federal do Paraná, Universidade Federal do Paraná, Curitiba, PR, Brasil

\section{Souza, Waldir}

Escola de Ciências da Vida, Programa de Pós-Graduação em Bioética da Pontifícia Universidade Católica do Paraná, Curitiba, PR, Brasil

PALAVRAS-CHAVE: cuidados paliativos, homossexualidade

A ideia de cuidado integral é um forte núcleo dos cuidados paliativos. Com isso, entende-se que o cuidado não se restringe unicamente à doença biológica, a saúde física do corpo, mas estende-se ao campo psicológico, moral e social do paciente, ou seja, o sujeito deixa de ser visto como recipiente de enfermidades para ser acolhido como um indivíduo integral. Com base nesta premissa, e levando em consideração o forte papel da orientação sexual na sociedade (que ganha contornos notórios na contemporaneidade), o presente trabalho objetivou, através de um estudo bibliográfico, investigar as intersecções entre cuidados paliativos e a homossexualidade masculina. Três problemas gerais foram identificados: 1) o luto diferenciado (silenciado) sofrido por homens que perdem seus parceiros, 2) as especificidades do envelhecimento de homens homossexuais, marcado pelo duplo estigma de ser idoso e não-heterossexual e 3) os possíveis preconceitos enraizados nos profissionais que se dedicam a cuidar de pacientes em fase terminal da vida. Conclui-se que, se a prática paliativa propõe um cuidado mais holístico, mais global, ela deve, como pressuposto, acolher a sexualidade dos pacientes, especialmente as sexualidades que se desviam da heteronorma, como a homossexualidade, por estarem, não raramente, perpassadas pela violência, pelo silêncio e pela negação. O profissional que se pretenda exercer uma prática paliativa, portanto, deve acolher estes indivíduos, pois o não acolhimento representara a anulação de uma parte significativa da vida destes homens, indo em contraposição aos princípios dos cuidados paliativos.

\section{REFERÊNCIAS}

[1] DOKA, K. J. Disenfranchised grief. In: DOKA, K. J. (Ed.), Disenfranchised grief: Recognizing hidden sorrow. New York, NY: Lexington, 1989. p. 3-11.

[2] HIGGINS, A.; GLACKEN, M. Sculpting the distress: easing or exacerbating the grief experience of same-sex couples. International Journal of Palliative Nursing, v. 15, n. 4, p. 170-176, 2009.

[3] MENEZES, R. A. Em Busca da Boa Morte: Antropologia dos Cuidados Paliativos. Rio de Janeiro: Garamond/Fiocruz, 2004.

[4] MOTA, M. P. Da. Homossexualidade e Envelhecimento: Algumas reflexões no campo da experiência. Sinais - Revista Eletrônica, v. 1, n. 6, p. 26 $51,2009$. 